\title{
Stratification of Stage III colon cancer may identify a patient group not requiring adjuvant chemotherapy
}

\author{
Yasir G. Malik ${ }^{1,2}$ - Lars Gustav Lyckander ${ }^{3}$. Jonas C. Lindstrøm ${ }^{4}$. Olof Vinge-Holmquist ${ }^{1} \cdot$ Ariba E. Sheikh $^{1}$. \\ Johannes K. Schultz ${ }^{1}$ - Dejan Ignjatovic ${ }^{1,2}$
}

Received: 4 June 2020 / Accepted: 1 September 2020 / Published online: 13 September 2020

(c) The Author(s) 2020

\begin{abstract}
Purpose Adjuvant chemotherapy for colon cancer with lymph node involvement (Stage III) has been the standard of care since the 1990s. Meanwhile, considerable evolvement of surgery combined with dedicated histopathological examinations may have led to stage migration. Furthermore, prognostic factors other than lymph node involvement have proven to affect overall survival. Thus, adjuvant chemotherapy in Stage III colon cancer should be reconsidered. The objective was to compare recurrence rates and survival in stage III colon cancer patients treated with or without adjuvant chemotherapy. Further, to assess the impact of extensive mesenterectomy, lymph node stage and vascular invasion on outcome.

Methods Consecutive patients operated for Stage III colon carcinoma between 31 December 2005 and 31 December 2015 were identified in the pathological code register by matching colon (T67) and either adenocarcinoma (M81403) or mucinous adenocarcinoma (M84803), with lymph node (T08) and metastasis of adenocarcinoma (M81406 or M84806). Medical records of all identified patients were reviewed.

Results Of 216 identified patients, 69 received no postoperative adjuvant chemotherapy (group NC), 69 insufficient adjuvant chemotherapy (FLV or $<$ minimum recommended 6 cycles FLOX, group IC), and 78 sufficient adjuvant chemotherapy ( $\geq 6$ cycles FLOX, group SC). When adjusted for age and comorbidity, 5-year overall survival did not differ statistically significant between groups ( $76 \%$ vs. $83 \%$ vs. $85 \%$, respectively). Vascular invasion and a high lymph node ratio significantly reduced overall survival.

Conclusion The findings imply that subgroups of Stage III colon cancer patients have good prognosis also without adjuvant chemotherapy. For definite conclusions about necessity of adjuvant chemotherapy, prospective trials are needed.
\end{abstract}

Keywords Stage III colon cancer $\cdot$ Adjuvant chemotherapy $\cdot$ Vascular invasion $\cdot$ Lymph node ratio $\cdot$ Complete mesocolic excision

Yasir G. Malik

Yasir.Gulzar.Malik@ahus.no

1 Department of Digestive Surgery, Akershus University Hospital, Sykehusveien 25, 1478 Lørenskog, Norway

2 Institute of Clinical Medicine, Faculty of Medicine, University of Oslo, Oslo, Norway

3 Department of Pathology, Akershus University Hospital, Lørenskog, Norway

4 Health Services Research Unit, Akershus University Hospital, Lørenskog, Norway

\section{Introduction}

Colon cancer is among the most common cancers worldwide (GBD 2017 Colorectal Cancer Collaborators 2019). In the past 60 years, the incidence of colon cancer in Norway has increased substantially, more prominently than in other Scandinavian countries. Since the 1970s, the 5-year relative survival has steadily improved, from under $30 \%$ in the 1960 s to over $60 \%$ at present. The 5 -year relative survival is above $90 \%$ for localized tumor (Stage I-II), and about $80 \%$ for locally advanced (Stage III) cancer, but only 10-20\% in cases with metastatic disease. The current Norwegian treatment algorithm for Stage III disease consists of surgery (central vessel ligation encouraged, but the extent of the mesenterectomy remains undefined) with addition of 
adjuvant chemotherapy if the patient is under 75 years of age. Patients between 70 and 75 years are usually offered monotherapy with either capecitabine (Xeloda) or 5-fluorouracil (FLV) whereas combination therapy is recommended for patients under the age of 70 years [N1: XELOX ( 6 cycles of capecitabine + oxaliplatin], N2: XELOX/FOLFOX/FLOX (12 cycles of 5-fluorouracil + oxaliplatin) (Helsedirektoratet 2019). These recommendations are mainly based on older studies (Laurie et al. 1989; Moertel et al. 1990). The treatment algorithm is adjusted in case of comorbidity or poor tolerance, but is otherwise not personalized.

Today, we are complicit witnesses of several attempts to personalize treatment for colon cancer, with the aim to improve outcomes. One such example is immunotherapy for microsatellite-instable (MSI) tumors (Weger et al. 2012). It is estimated that adjuvant treatment in Stage III disease improves 5-year overall survival (OS) by 7-8\% (Gill et al. 2004). However, many other risk factors for recurrence apart from $\mathrm{N}$ stage have been identified [i.e., vascular invasion (Leijssen et al. 2019), T stage (Li et al. 2018), perineural invasion (Yang et al. 2015), genetic factors (Antelo et al. 2012)] and it is quite likely that the effect of adjuvant therapy varies considerably within the Stage III group. Furthermore, surgery has evolved towards more radical methods since the introduction of adjuvant chemotherapy and some Stage III patients might, therefore, be overtreated when following current guidelines for adjuvant chemotherapy.

The aim of this study was to compare OS and recurrence rates after surgery for Stage III colon cancer in patients who $\mathrm{did} / \mathrm{did}$ not receive adjuvant chemotherapy. Furthermore, the impact of the extent of mesenterectomy as well as lymph node stage and vascular invasion (VI) was assessed.

\section{Materials and methods}

In this single-center quality control cohort study, all patients operated for colon cancer with lymph node involvement between 31 December 2005 and 31 December 2015 at Akershus University hospital were eligible. Exclusion criteria were distant metastasis at the time of diagnosis, tumor perforation, death due to postoperative complications, nonradical surgery (R1, R2), relocation to an address outside the Akershus University hospital recruitment area after surgery and insufficient CT staging (emergency surgery).

All patients treated for Stage III colon cancer during the study period were identified from the pathology laboratory information system (DocuLive Pathology, Cerner) using a search module (Pat Stat) to identify SNOMED codes for topography (T-code T67 for colon) and morphology (M-code M81403 for adenocarcinoma or M 84803 for mucinous adenocarcinoma). All of these patients who at the same time period were registered with lymph node
(T08) combined with metastasis of either adenocarcinoma (M81406) or mucinous adenocarcinoma (M84806) were included in the trial. The lists of patients registered with these codes were provided by the pathologist and handled by the Data capture group at Akershus University Hospital.

Clinical data were collected by review of patient files (YM, OV-H and AS) using the electronic medical record system DIPS (Copyright 1995-2016 DIPS ASA version 7.395). The baseline variables included demographic data, ASA (American Society of Anesthesiologists) classification (ASA 2014) and Charlson comorbidity index (CCI) (Charlson et al. 1987). Treatment-related variables included data concerning the surgical intervention and adjuvant chemotherapy, including types and number of received chemotherapy cycles, which in turn laid the foundation for the study population to be divided into three groups:

Group 1: no chemotherapy (NC), Group 2: insufficient chemotherapy (IC, i.e., less than minimum recommended in Norway-either FLV (monotherapy) or less than six cycles of FLOX), Group 3: sufficient chemotherapy [SC; a minimum of six cycles of FLOX as recommended (Iveson et al. 2019)]. The extent of the lymph node dissection (D2 or D3) was registered. For left-sided colectomy and sigmoid resection, D3 was defined as central IMA (inferior mesenteric artery) ligation (proximal to the left colic artery). A rightsided colectomy was defined as D3 only if all lymphatic tissue anterior and posterior to the superior mesenteric vessels was removed, as for patients included in the clinical trial "Safe Radical D3 Right Hemi colectomy for Cancer through Preoperative Biphasic Multi-Detector Computed Tomography (MDCT) Angiography" (ClinicalTrials.gov identifier: NCT01351714) (Gaupset et al. 2018; Nesgaar et al. 2019), which enrolled patients since 2011 at Akershus University Hospital.

Data about tumor biology included tumor size, differentiation, morphology, total number of lymph nodes removed, number of lymph nodes with metastasis, T stage (TNM classification, 8th edition) (Brierley Wittekind 2017) and vascular invasion (VI). VI was not regularly reported during the study period and did not differentiate between extramural vascular invasion (EMVI) and intramural vascular invasion (IMVI). A single experienced GI-pathologist (LGL) reanalyzed the original slides of patients with missing data on vascular invasion, according to the latest guidelines of The Royal College of Pathologists (RCPath 2020).

The outcome measures included type of recurrence based on first CT scan showing recurrence, time to last CT scan during the follow-up and time to death.

Ethical approval for this study was applied for at the Regional Ethics Committee (REC) South East Norway. The reply stated that ethical approval was not required as this is a local retrospective quality control study (Reference 2016/1285 REC South East B). Approval was given by the 
data protection officer (nr: 16-128) at Akershus University Hospital.

\section{Statistical analysis}

Demographic variables were analyzed using $t$ tests and chi-square test. Time from surgery to recurrence or death was analyzed using Cox regression modeling. In time-torecurrence analyses, deaths were censored. Adjustments for age and comorbidity (CCI) were done by adding them as covariates in the Cox model. The Cox models were also used to estimate 5-year survival, and adjusted 5-year survival estimates were presented for age $=62$ and $\mathrm{CCI}=2.5$, which were about the mean values for these variables. All statistical analyses were done in $\mathrm{R}$ version 3.6 ( $\mathrm{R}$ core team 2013).

\section{Results}

A total of 397 patients operated for colon cancer with lymph node metastasis during the study period were identified. After the exclusion of 181 patients (various reasons, Fig. 1), 216 patients were eligible for inclusion, of these 69 patients (group NC) did not receive chemotherapy, 69 patients (group IC) received either FLV or $<6$ cycles FLOX, and the remaining 78 patients (group SC) received at least 6 FLOX cycles, Fig. 1.

Descriptive statistics for the baseline characteristics of the three groups are presented in Table 1 . Statistically significant differences between the groups were found in age $(p<0.001$ between all three groups) and CCI scores ( $p<0.002$ between all three groups). In the SC group, $91 \%$ of patients had no comorbidity at all compared to $72 \%$ in the IC group and $42 \%$ in the $\mathrm{NC}$ group.
The results of surgery and outcomes are presented in Table 2. T stage, VI and D2/D3 dissection were equally distributed between the groups. Regarding tumor biology, $16 \%$ of the patients had low differentiated adenocarcinoma in the NC group, $23 \%$ in the IC group, and 10\% in the SC group; these differences were not statistically significant and the groups were comparable for tumor size and morphology. Mean total lymph node harvest was comparable in all three groups (23.2 group NC; 25.4 group IC and 27.4 group SC). Significantly more lymph nodes were harvested with $\mathrm{D} 3$ dissection compared to D2 dissection (36.3 vs $21.9 ; p<0.001$ ). There were less patients with $\mathrm{N} 2$ status in group NC (26\%) and IC (24\%) compared to group SC (39\%); these differences were not statistically significant. Lymph node ratios (metastatic lymph nodes/harvested lymph nodes) in the three groups were comparable. No significant difference in lymph node ratio (LNR) was found for patients with D2 dissection (0.18) compared to D3 dissection (0.12). There was a significant difference in recurrence rate between groups $\mathrm{NC}$ and SC (39\% vs $17 \% ; p=0.004)$, and no significant difference between groups NC and IC (39\% vs $29 \%$ ) and IC and SC. Of 60 patients with recurrences, 16 were operated for their recurrence with curative intent (group NC: 4, group IC: 5 , group SC: 7 ) and six of these did not have any further relapse (group NC: 1 , group IC: 2 , group SC: 3 ).

The crude 5-year OS (44\% for group NC, $76 \%$ for group IC and $86 \%$ for group SC) differed significantly between groups SC and NC (HR: 3.09, CI: 1.40-6.80, $p=0.005$ ) and not significantly between groups SC and IC (HR: 1.48 , CI: $0.63-3.48, p=0.37$ ). After adjusting for age and CCI no significant differences were found in 5-year OS (group NC: $76 \%$, group IC: $83 \%$, group SC: $85 \%$; between groups SC and NC: HR 1.70, CI: $0.53-5.42, p=0.37$; between groups SC and IC: HR 1.15, CI: 0.45-2.92, $p=0.78)$, Fig. 2.
Fig. 1 Study flow diagram with exclusions

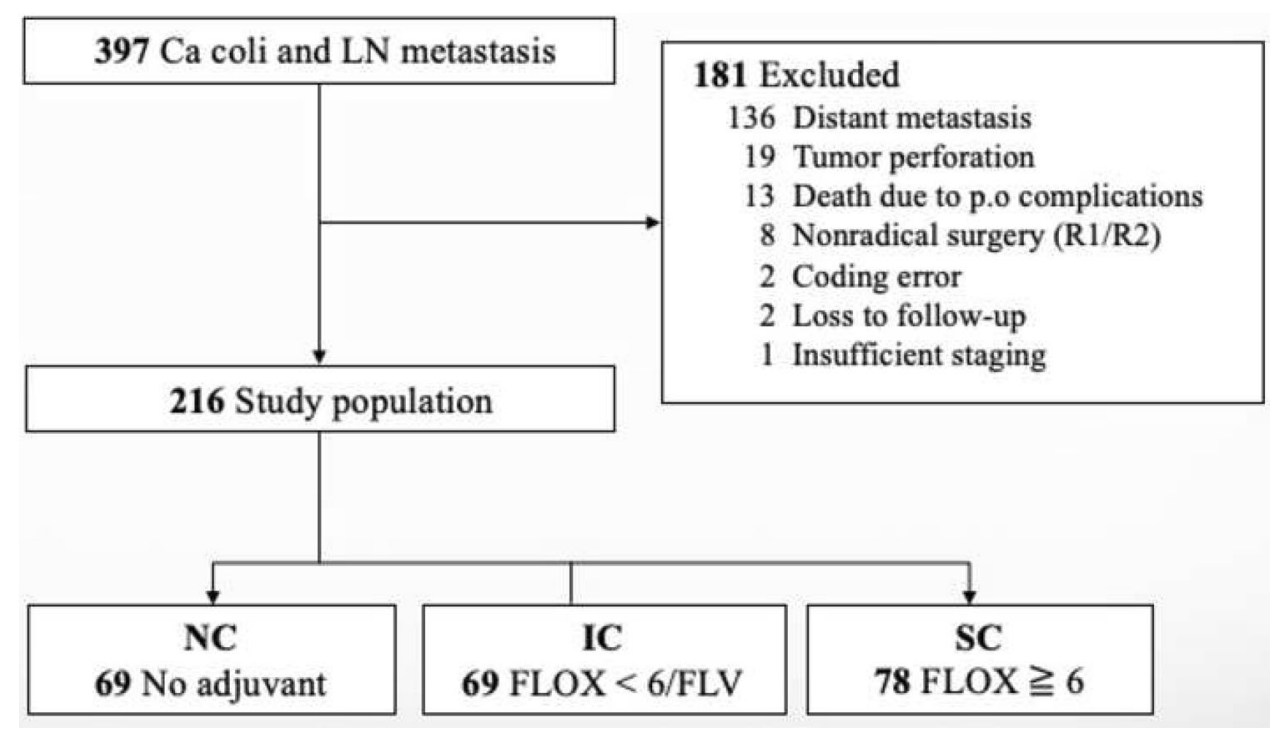


Table 1 Baseline characteristics

\begin{tabular}{|c|c|c|c|c|}
\hline & $\begin{array}{l}\text { All patients } \\
(n=216)\end{array}$ & $\begin{array}{l}\text { Group NC } \\
(n=69)\end{array}$ & $\begin{array}{l}\text { Group IC } \\
(n=69)\end{array}$ & $\begin{array}{l}\text { Group SC } \\
(n=78)\end{array}$ \\
\hline \multicolumn{5}{|l|}{ Sex } \\
\hline Male & $95(44 \%)$ & $38(55 \%)$ & $27(39 \%)$ & $30(39 \%)$ \\
\hline Female & $121(56 \%)$ & $31(45 \%)$ & $42(61 \%)$ & $48(61 \%)$ \\
\hline Age, mean (SD) (years) & $67.5(11.4)$ & $77.8(7.2)$ & $67.2(7.2)$ & $58.8(9.9)$ \\
\hline BMI, mean (SD) $\left(\mathrm{kg} / \mathrm{m}^{2}\right)$ & $25.3(4.5)$ & $24.6(3.7)$ & $25.7(5.3)$ & $25.4(4.4)$ \\
\hline Missing & $23(11 \%)$ & $9(13 \%)$ & $6(9 \%)$ & $8(10 \%)$ \\
\hline \multicolumn{5}{|l|}{ Comorbidity } \\
\hline None & $150(69 \%)$ & $29(42 \%)$ & $50(72 \%)$ & $71(91 \%)$ \\
\hline Ischemic heart disease or heart failure & $25(12 \%)$ & $17(25 \%)$ & $6(9 \%)$ & $2(3 \%)$ \\
\hline Chronic pulmonary disease & $9(4 \%)$ & $6(9 \%)$ & $2(3 \%)$ & $1(1 \%)$ \\
\hline Cerebrovascular disease & $12(6 \%)$ & $11(16 \%)$ & $0(0 \%)$ & $1(1 \%)$ \\
\hline Diabetes & $21(10 \%)$ & $9(13 \%)$ & $9(13 \%)$ & $3(4 \%)$ \\
\hline Other comorbidity & $17(8 \%)$ & $10(14 \%)$ & $7(10 \%)$ & $0(0 \%)$ \\
\hline \multicolumn{5}{|l|}{ ASA physical status score ${ }^{d}$} \\
\hline I & $16(7 \%)$ & $1(1 \%)$ & $4(6 \%)$ & $11(14 \%)$ \\
\hline II & $66(31 \%)$ & $17(25 \%)$ & $21(30 \%)$ & $28(36 \%)$ \\
\hline III & $49(23 \%)$ & $25(36 \%)$ & $20(29 \%)$ & $4(5 \%)$ \\
\hline IV & $4(2 \%)$ & $4(6 \%)$ & $0(0 \%)$ & $0(0 \%)$ \\
\hline Missing & $81(37 \%)$ & $22(31 \%)$ & $24(35 \%)$ & $35(45 \%)$ \\
\hline CCI score, mean (SD) & $2.5(0.8)$ & $2.9(1.0)$ & $2.4(0.7)$ & $2.1(0.3)$ \\
\hline \multicolumn{5}{|l|}{ Tumor localization } \\
\hline Caecum, ascending colon & $82(38 \%)$ & $27(39 \%)$ & $24(35 \%)$ & $31(40 \%)$ \\
\hline Transversum, flexures & $51(23 \%)$ & $18(26 \%)$ & $19(27 \%)$ & $14(18 \%)$ \\
\hline Sigmoid, descending colon & $83(38 \%)$ & $24(35 \%)$ & $26(38 \%)$ & $33(42 \%)$ \\
\hline
\end{tabular}

$S D$ standard deviation, $B M I$ body-mass index, ASA American Society of Anesthesiologists, $C C I$ Charlson comorbidity index

${ }^{\mathrm{a}}$ Group $\mathrm{NC}=$ No adjuvant

${ }^{\mathrm{b}}$ Group IC $=$ FLOX $<6$ or FLV

${ }^{\mathrm{c}}$ Group $\mathrm{SC}=\mathrm{FLOX} \geq 6$

${ }^{\mathrm{d}}$ Anesthesiological comorbidity score; score range I to V; I indicates completely healthy, V indicates moribund

After correction for age and CCI, 5-year OS for patients operated with D2 or D3 dissection was $71 \%$ vs $93 \%$ in group NC (HR: 0.37 , CI: $0.02-6.73, p=0.50), 86 \%$ vs $77 \%$ in group IC (HR: 3.06, CI: 0.28-34.02, $p=0.36$ ) and $85 \%$ vs $91 \%$ in group SC (HR: 0.56, CI: 0.07-4.41, $p=0.58$ ), Fig. 3.

The observed difference in time to recurrence between D2 and D3 operated patients (HR: 0.47, CI: 0.22-0.99, $p=0.047$ ) was statistically significant, Fig. 4.

The estimated 5-year overall survival depending on the LNR was $76 \%$ for LNR $0.05 ; 74 \%$ for LNR $0.1 ; 68 \%$ for LNR 0.2 and $20 \%$ for LNR 0.8, Fig. 5.

The difference in 5-year overall survival for patients with VI $(52 \%)$ and without VI (81\%) was significant (HR: 2.16, CI: $1.40-3.34, p=0.001)$, Fig. 6.

D3 dissection was performed on 7 patients (13\%) between 2005 and 2010, and on 46 patients (87\%) between 2011 and 2015. When broken down according to the extent of lymph node dissection (D2/D3) and VI (yes/no), the results presented in Fig. 7 demonstrate that the recurrence rate in patients with VI was $23 \%$ when operated with D3, and $43 \%$ when operated with D2. In VI negative patients, recurrences occurred in $9 \%$ of the patients after D3 operation and $23 \%$ after D2 operation. These differences were not statistically significant.

\section{Discussion}

This single-center retrospective cohort study showed crude 5-year overall survival (OS) in patients operated for Stage III colon cancer was best after adjuvant chemotherapy. However, when adjusted for age and comorbidity, the differences between the groups were not statistically significant. Vascular invasion (VI) and lymph node ratio (LNR) had a significant impact on overall survival as independent prognostic factors. Time to recurrence was significantly longer after 
Table 2 Surgery and outcomes

\begin{tabular}{|c|c|c|c|c|}
\hline & $\begin{array}{l}\text { All patients } \\
(n=216)\end{array}$ & $\begin{array}{l}\text { Group NC } \mathrm{NC}^{\mathrm{a}} \\
(n=69)\end{array}$ & $\begin{array}{l}\text { Group IC } \\
(n=69)\end{array}$ & $\begin{array}{l}\text { Group SC } \mathrm{SC}^{\mathrm{c}} \\
(n=78)\end{array}$ \\
\hline \multicolumn{5}{|l|}{ Surgery } \\
\hline D2 dissection & $163(75 \%)$ & $53(77 \%)$ & $48(70 \%)$ & $62(79 \%)$ \\
\hline D3 dissection & $53(25 \%)$ & $16(23 \%)$ & $21(30 \%)$ & $16(21 \%)$ \\
\hline Total LN, mean (SD) & $25.4(15.3)$ & $23.2(14)$ & $25.4(16.4)$ & $27.4(15.2)$ \\
\hline \multicolumn{5}{|l|}{ Positive LN } \\
\hline N1a & $71(33 \%)$ & $28(41 \%)$ & $24(35 \%)$ & $19(24 \%)$ \\
\hline N1b & $80(37 \%)$ & $23(33 \%)$ & $28(41 \%)$ & $29(37 \%)$ \\
\hline $\mathrm{N} 2$ & $65(30 \%)$ & $18(26 \%)$ & $17(24 \%)$ & $30(39 \%)$ \\
\hline LN ratio, mean (SD) & $0.16(0.16)$ & $0.19(0.20)$ & $0.14(0.12)$ & $0.16(0.14)$ \\
\hline Vascular invasion & $95(44 \%)$ & $29(42 \%)$ & $32(46 \%)$ & $34(44 \%)$ \\
\hline Missing & $4(2 \%)$ & $3(4 \%)$ & $1(1 \%)$ & $0(0 \%)$ \\
\hline \multicolumn{5}{|l|}{ T-stage $^{\mathrm{d}}$} \\
\hline $\mathrm{T} 1$ & $3(1 \%)$ & $0(0 \%)$ & $0(0 \%)$ & $3(4 \%)$ \\
\hline $\mathrm{T} 2$ & $16(7 \%)$ & $4(6 \%)$ & $5(7 \%)$ & $7(9 \%)$ \\
\hline $\mathrm{T} 3$ & $137(63 \%)$ & $47(68 \%)$ & $43(62 \%)$ & $47(60 \%)$ \\
\hline $\mathrm{T} 4$ & $47(22 \%)$ & $14(20 \%)$ & $17(25 \%)$ & $16(21 \%)$ \\
\hline $\mathrm{T} 4 \mathrm{~b}$ & $12(6 \%)$ & $4(6 \%)$ & $4(6 \%)$ & $4(5 \%)$ \\
\hline \multicolumn{5}{|l|}{ Follow-up in months } \\
\hline To last CT, mean (SD) & $40.0(25.2)$ & $25.2(18.7)$ & $43.9(25.4)$ & $48.5(24.6)$ \\
\hline Missing & $13(6 \%)$ & $8(12 \%)$ & $4(6 \%)$ & $1(1 \%)$ \\
\hline Clinical, mean (SD) & $63.9(39.2)$ & $42.6(30.2)$ & $65.8(39.4)$ & $81.0(37.4)$ \\
\hline \multicolumn{5}{|l|}{ Recurrence $^{\mathrm{e}}$} \\
\hline Total & $60(28 \%)$ & $27(39 \%)$ & $20(29 \%)$ & $13(17 \%)$ \\
\hline Liver metastasis & $17(28 \%)$ & $10(37 \%)$ & $3(15 \%)$ & $4(31 \%)$ \\
\hline Lung metastasis & $6(10 \%)$ & $0(0 \%)$ & $4(20 \%)$ & $2(15 \%)$ \\
\hline Peritoneal Carsinomatosis & $8(13 \%)$ & $4(15 \%)$ & $2(10 \%)$ & $2(15 \%)$ \\
\hline Local recurrence & $2(3 \%)$ & $1(4 \%)$ & $1(5 \%)$ & $0(0 \%)$ \\
\hline Multiple metastasis & $14(23 \%)$ & $7(26 \%)$ & $5(25 \%)$ & $2(15 \%)$ \\
\hline Other metastasis & $13(22 \%)$ & $5(19 \%)$ & $5(25 \%)$ & $3(23 \%)$ \\
\hline
\end{tabular}

$S D$ standard deviation, $L N$ Lymph node, N1a tumor cells in 1 regional lymph node, $N 1 b$ tumor cells in 2 or 3 regional lymph nodes, $N 2$ : tumor cells in more than 3 regional lymph nodes, $T$-stage tumor stage

${ }^{\mathrm{a}}$ Group $\mathrm{NC}=$ No adjuvant

${ }^{\mathrm{b}}$ Group IC $=\mathrm{FLOX}<6$ or FLV

${ }^{\mathrm{c}}$ Group SC $=\mathrm{FLOX} \geq 6$

${ }^{\mathrm{d}} \mathrm{T}$-stage not defined for 1 patient in Group SC

ebased on first CT scan showing recurrence

more extensive lymph node dissection (D3) compared to less extensive lymph node dissection $(p=0.047)$; however, the extent of lymph node dissection did not have a significant impact on 5-year OS.

In Norway, adjuvant chemotherapy is generally recommended after operation for Stage III colon cancer (Helsedirektoratet 2019). Comorbid and older patients ( $>75$ years) are usually not offered adjuvant chemotherapy, and a few patients even deny chemotherapy due to various reasons. This creates a significant selection bias in this cohort with effect on survival, which is clearly reflected in the results of this study. This explains why the large difference in crude overall survival is not statistically significant after the adjustment for age and CCI. One may argue that the observed difference in adjusted 5-year OS was not significant due to the small sample size. However, our findings are in line with a Scandinavian multicenter randomized trial, published in 2005 , comparing surgery alone to surgery with adjuvant chemotherapy which showed no significant difference in OS (Glimelius et al. 2005).

The first recommendations for adjuvant therapy from the US National Cancer Institute (NCI) Consensus Conference (Adjuvant therapy for patients with colon and rectum cancer 1990) in 1990 were mainly based on two 
Fig. 2 Estimated 5-year overall survival adjusted for age and $\mathrm{CCI}($ age $=68$ and $\mathrm{CCI}=2.5$ ) based on Cox regression

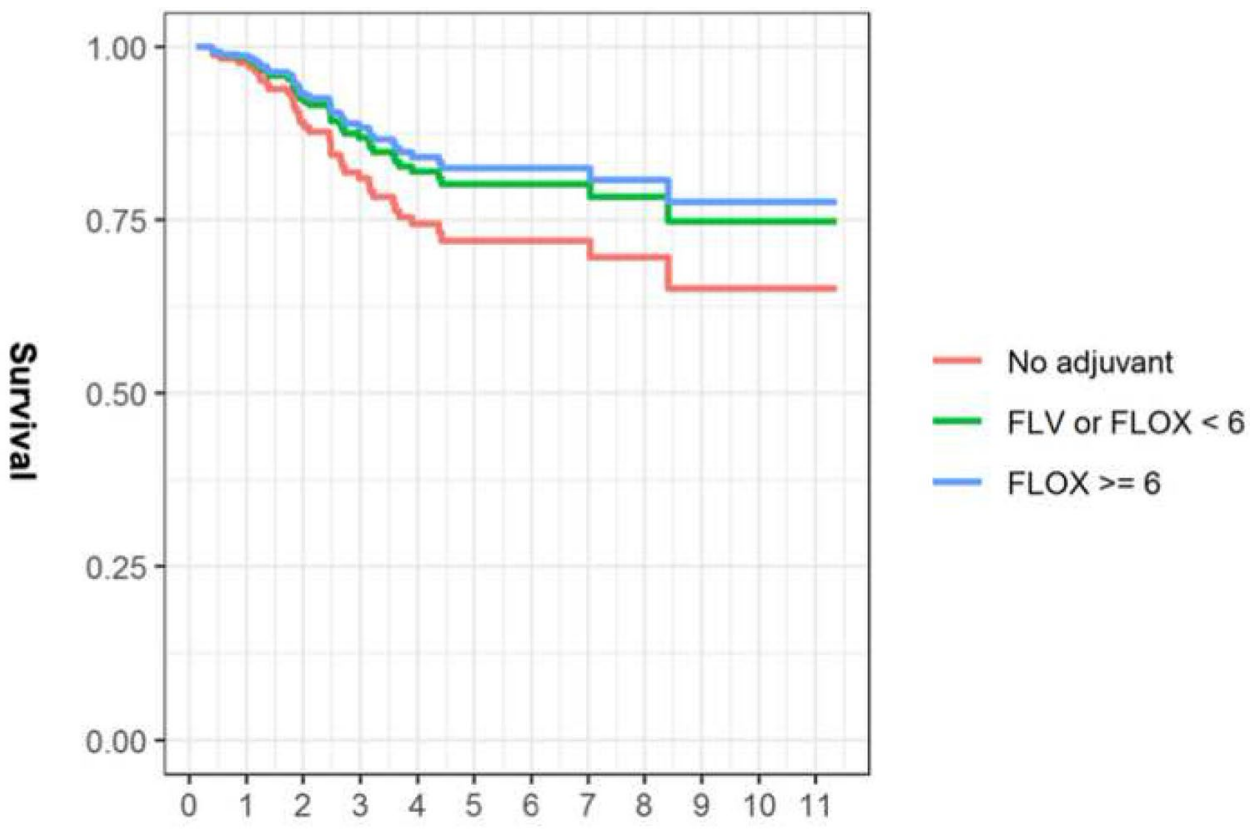

Years

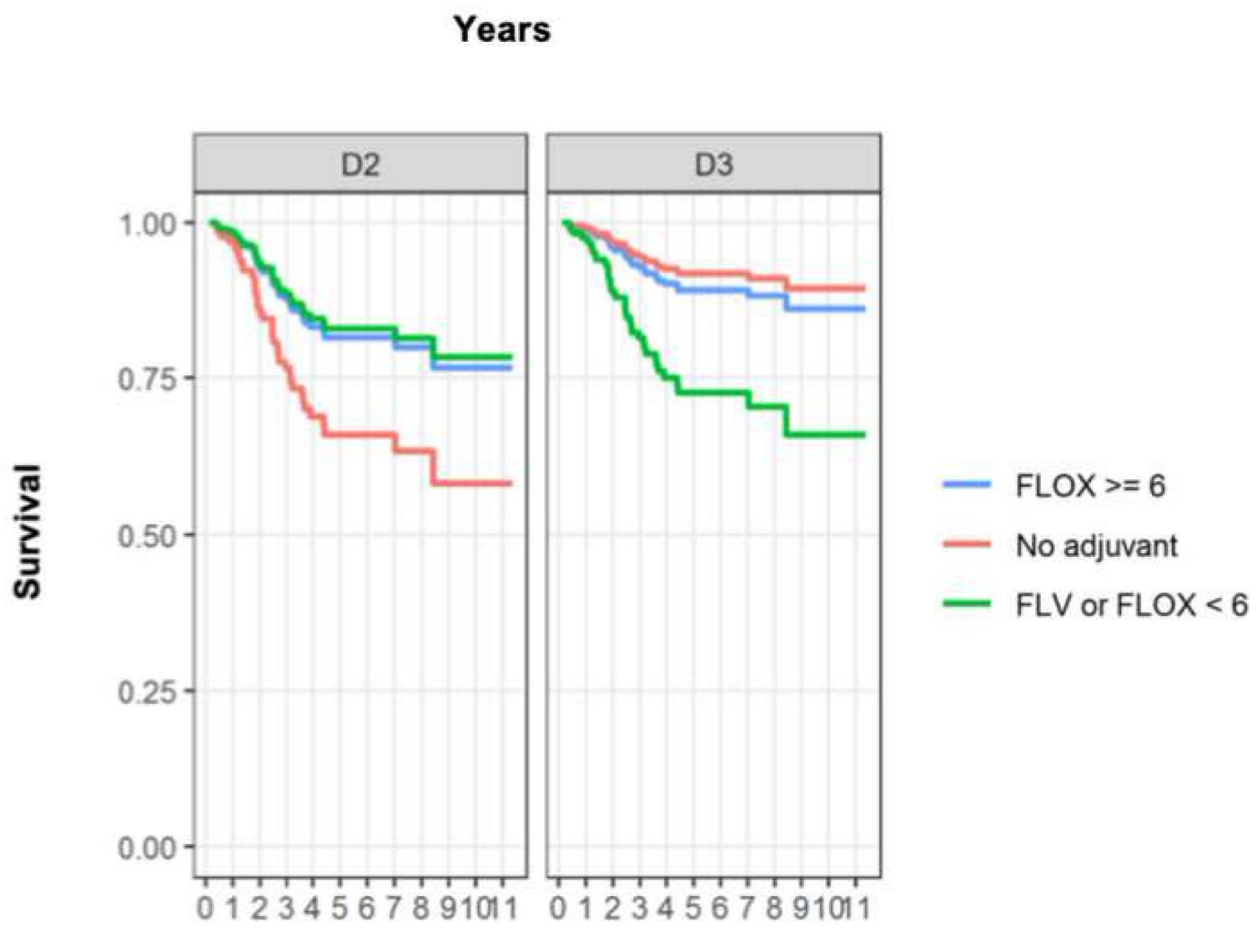

Years
Fig. 3 Estimated 5-year overall survival for D2 and D3 operated patients adjusted for age and CCI (age $=68$ and $\mathrm{CCI}=2.5$ ) based on Cox regression studies (Laurie et al. 1989; Moertel et al. 1990). Later, mostly the differences between different adjuvant regimes have been investigated. It is quite likely that the operative technique has become more radical since the RCTs conducted in the 1990s. The increased focus on lymph node harvest throughout the years has also resulted in a more intense search for lymph nodes within the specimen by the pathologist, possibly leading to stage migration and more extensive use of adjuvant chemotherapy. Furthermore, other risk factors than lymph node involvement have been shown to play a significant role for prognosis. In the light of this and our findings, one must question whether lymph node involvement alone should prompt adjuvant therapy in the future. 
Fig. 4 Time to recurrence in D2 and D3 operated patients
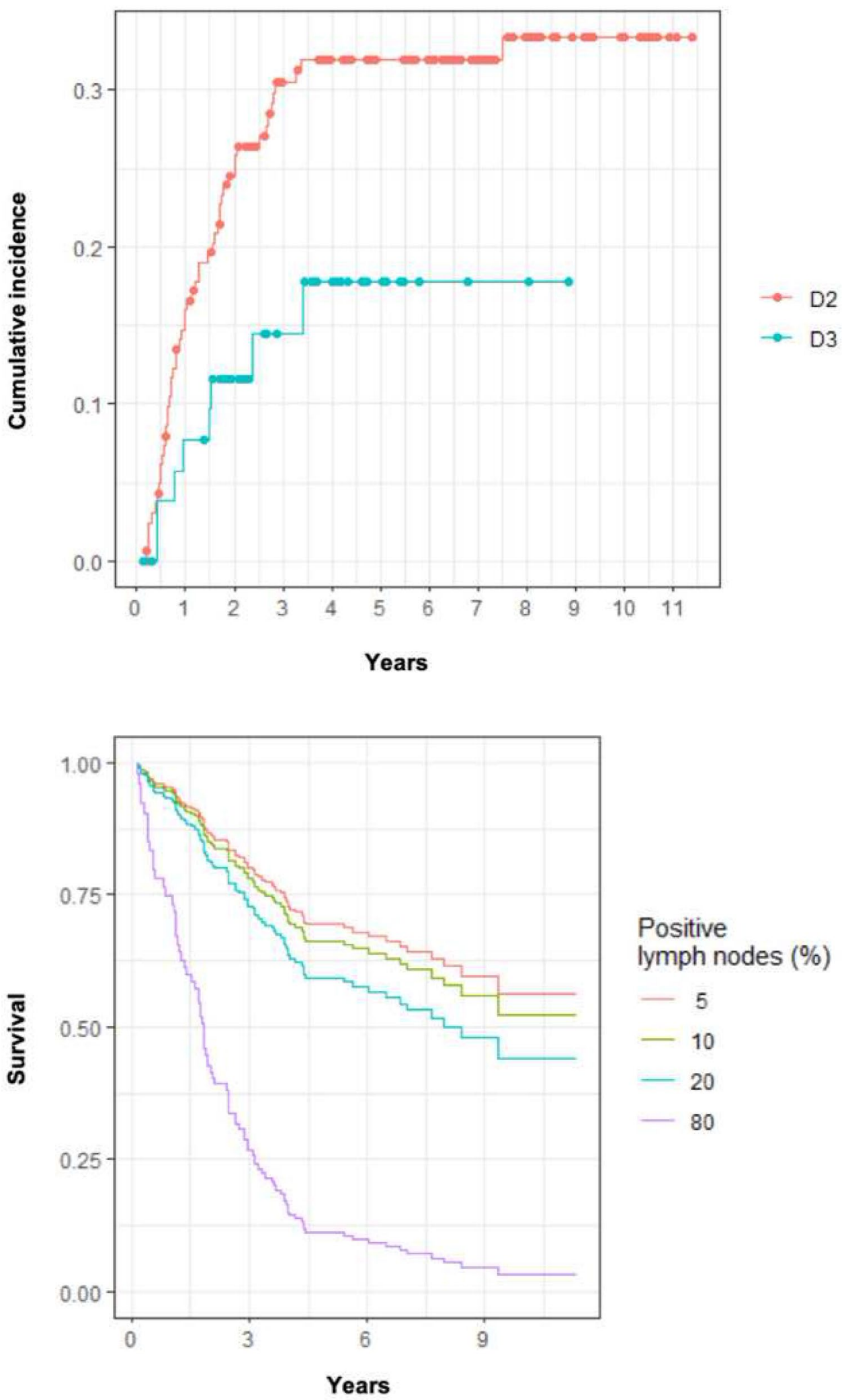

Fig. 5 Estimated 5-year overall survival for different lymph node ratios based on Cox regression
EMVI has been recognized to be a strong predictor for poor oncologic outcome in Stage II-III colon cancer patients, while IMVI is not. This association seems to be stronger than that for Lymph node involvement (Leijssen et al. 2019). In our study, a certain distinction between EMVI and IMVI was only used for the 110 patients for 
Fig. 6 Kaplan-Meier curve showing 5-year overall survival for patients with or without vascular invasion
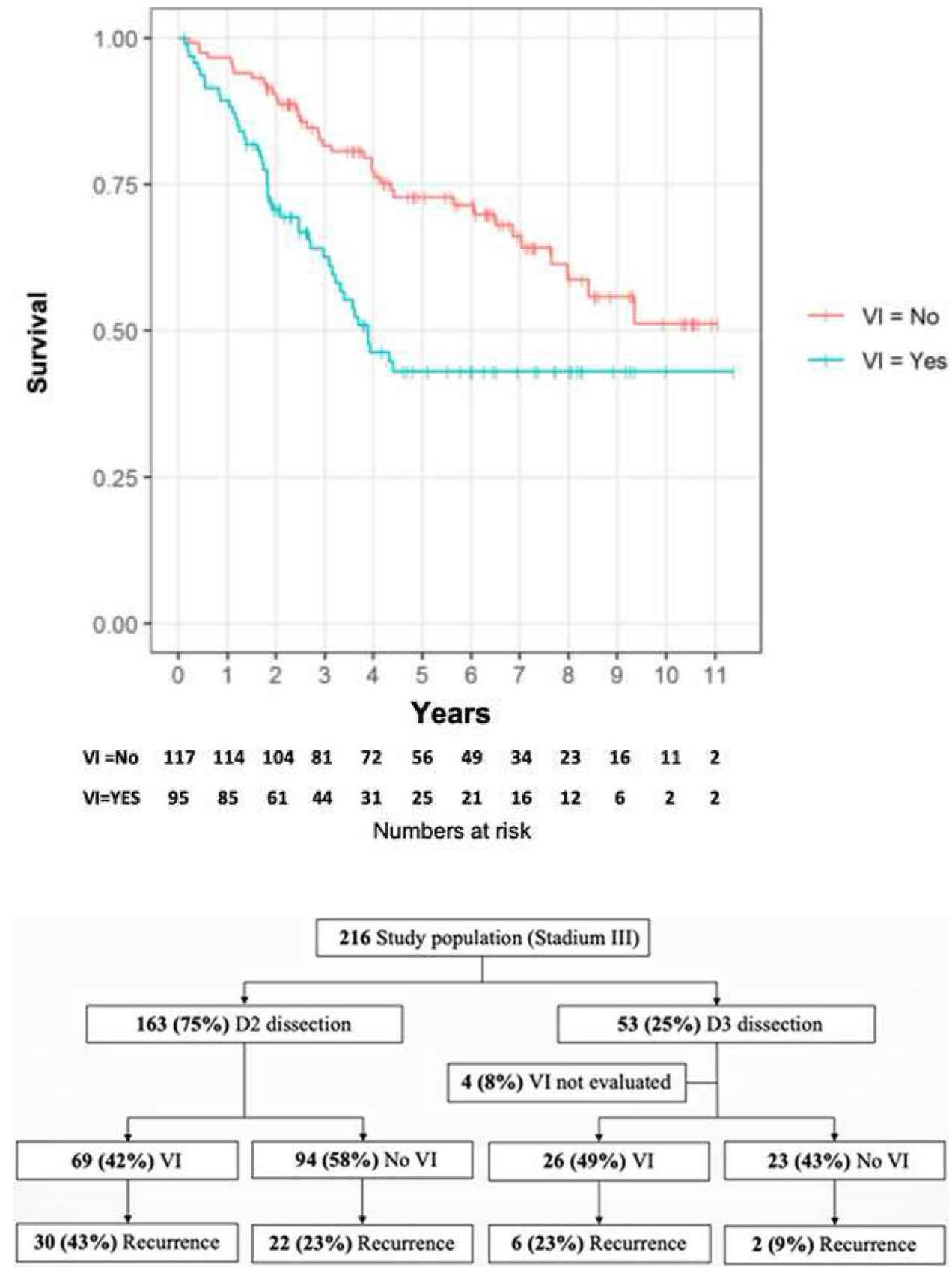

Fig. 7 Flow diagram of correlation between D2/D3 dissection and vascular invasion the "holy plane" during the 90 s, which leads to a decisive improvement of oncologic outcomes (Heald 1988). In fact, ESMO (European Society of Medical Oncology) does recommend not to base the decision for adjuvant chemotherapy of rectal cancer patients only on positive lymph nodes in the mesorectum (Glynne-Jones et al. 2017) and there is substantial variation in the use of this treatment in clinical practice (Bregni et al. 2020). Recently, "complete mesocolic excision" (CME) which follows the same principles as TME has been introduced for colon cancer, and several studies worldwide show a trend towards better survival (Hohenberger et al. 2009; Bertelsen et al. 2015). 
As new knowledge on the spreading mechanisms of colon cancer is acquired, consciousness of the extent of mesenterectomy is in focus. It is noted in the literature that a minimum of $2-4 \%$ of all patients with colon cancer have centrally located lymph node metastases (Kim et al. 2004). Very few authors have a clear anatomical definition for these nodes (Spasojevic et al. 2013; Nesgaard et al. 2018). Today, the Norwegian national guidelines encourage that D3 (extended lymphadenectomy with central vessel ligation) should be performed, while D2 (limited lymphadenectomy with intermediate ligation of colonic vessels) represents the minimal requirement (Helsedirektoratet 2019). Several studies have shown that higher number of lymph nodes in the specimen are associated with better survival (Voyer et al. 2003; Swanson et al. 2003; Chen and Bilchik 2006; Kelder et al. 2009; Goldstein 2002). This entails more attention to the LNR in the future, which has a significant impact on survival as clearly illustrated in our study (Fig. 5), in accordance with previous studies (Berger et al. 2005; Rosenberg et al. 2008).

D3 dissection was a rarity in the first half of the study period but gradually became more common in the second half of the study period ( $13 \%$ vs $87 \%)$, mainly due to the introduction of a standardized approach with central vessel ligation for left-sided tumors and the start of the clinical trial "Safe Radical D3 Right Hemi-colectomy for Cancer through Preoperative Biphasic Multi-Detector Computed Tomography (MDCT) Angiography" (Gaupset et al. 2018; Nesgaar et al. 2019). In this trial, extensive lymphadenectomy is performed removing not only tissue located anterior but also posterior to the superior mesenteric vessels, this not being the case in D2 dissection. A recent study where conventional laparoscopic right hemi-colectomy was performed has shown that patients with an ileocolic artery (ICA) crossing posteriorly to the superior mesenteric vein (SMV) have worse disease-free survival (DFS) when compared to those with ICA crossing anteriorly (Ishiyama et al. 2020). It has recently also been demonstrated that lymph node distribution anterior or posterior to the superior mesenteric vessels highly depends on the crossing pattern of the ICA (Spasojevic et al. 2013; Nesgaard et al. 2018), which implies that inadequate lymphadenectomy (D2 dissection) may be the reason for worse outcome in patients with a posterior ICA crossing.

Our results show a tendency to better survival after D3 dissection compared to D2 dissection in the NC group, while there is not much difference in the two groups which received adjuvant chemotherapy. The observed recurrence rates in patients operated with D3 compared to D2 were also lower both for patients with or without VI (Fig. 7). Although not statistically significant, these differences might indicate better outcome for patients operated with D3 dissection.

Some studies have shown that the presence of circulating tumor DNA (ctDNA) after resection of Stage II and III colon cancer is associated with higher risk of recurrence (Tie et al. 2016, 2019). However, recurrences were also detected in patients where ctDNA was not found, underlining the importance of combining other prognostic factors (discussed in this paper) with ctDNA to help in adjuvant treatment decisions in the future.

This study has several weaknesses mostly owing to its retrospective design. One major drawback of the design is that the patient groups are not comparable with respect to age and comorbidity due to a well-established clinical practice for adjuvant chemotherapy based on the Norwegian national guidelines. There is also a slight possibility that patients were treated for recurrences elsewhere. However, as cancer treatment and emergency surgery for patients in Norway usually are done at the local hospital, treatment at other sites are normally reported to the local hospital. Patients $(n=2)$ who moved out of the catchment area of Akershus University Hospital were, therefore, excluded. Furthermore, recurrences appearing after the last registered CT scan may have occurred undetected. Nevertheless, this was a pilot study to evaluate the feasibility of omitting adjuvant chemotherapy in selected patients with Stage III colon cancer and a retrospective design was, therefore, the most appropriate.

As the sample size was small, no definite conclusions can be drawn from this study. One could argue that a multicenter design or a registry study would have gathered a larger sample size; however, the information about individual patients in the registries is not detailed enough for the purpose of this study. The main strength of the study is the inclusion of all consecutive Dukes C patients who fulfilled the inclusion criteria in a given time period increasing the external validity of the study.

\section{Conclusion}

The retrospective design and limited sample size of this study precludes any conclusions about the necessity of chemotherapy. However, the findings imply that prognosis for subgroups of Stage III colon cancer patients is good also without chemotherapy, which in turn bears a significant risk of morbidity and even mortality (Andre et al. 2004). Prospective trials to evaluate the benefit of chemotherapy for these subgroups of Stage III colon cancer are needed.

Funding Open Access funding provided by University of Oslo (incl Oslo University Hospital).

Availability of data and material Available upon request. 


\section{Compliance with ethical standards}

Conflict of interest No conflicts of interest/competing interests to declare.

Ethics approval This is an observational quality control study. The Regional Ethics Committee (REC) South East Norway has confirmed that no ethical approval is required.

Open Access This article is licensed under a Creative Commons Attribution 4.0 International License, which permits use, sharing, adaptation, distribution and reproduction in any medium or format, as long as you give appropriate credit to the original author(s) and the source, provide a link to the Creative Commons licence, and indicate if changes were made. The images or other third party material in this article are included in the article's Creative Commons licence, unless indicated otherwise in a credit line to the material. If material is not included in the article's Creative Commons licence and your intended use is not permitted by statutory regulation or exceeds the permitted use, you will need to obtain permission directly from the copyright holder. To view a copy of this licence, visit http://creativecommons.org/licenses/by/4.0/.

\section{References}

Adjuvant therapy for patients with colon and rectum cancer (1990). Consens Statement 8(4):1-25

Andre T, Boni C, Mounedji-Boudiaf L, Navarro M, Tabernero J, Hickish T, Topham C, Zaninelli M, Clingan P, Bridgewater J, TabahFisch I, de Gramont A (2004) Oxaliplatin, fluorouracil, and leucovorin as adjuvant treatment for colon cancer. $\mathrm{N}$ Engl J Medicine 350(23):2343-2351. https://doi.org/10.1056/NEJMoa032709

Antelo M, Balaguer F, Shia J, Shen Y, Hur K, Moreira L, Cuatrecasas M, Bujanda L, Giraldez MD, Takahashi M, Cabanne A, Barugel ME, Arnold M, Roca EL, Andreu M, Castellvi-Bel S, Llor X, Jover R, Castells A, Boland CR, Goel A (2012) A high degree of LINE-1 hypomethylation is a unique feature of early-onset colorectal cancer. PLoS ONE 7(9):e45357. https://doi.org/10.1371/ journal.pone. 0045357

ASA (2014) ASA Physical Status Classification System https://www. asahq.org/ /media/sites/asahq/files/public/resources/standardsguidelines/asa-physical-status-classification-system.pdf (Cited Feb 2005 2020)

Berger AC, Sigurdson ER, LeVoyer T, Hanlon A, Mayer RJ, Macdonald JS, Catalano PJ, Haller DG (2005) Colon cancer survival is associated with decreasing ratio of metastatic to examined lymph nodes. J Clin Oncol 23(34):8706-8712. https://doi.org/10.1200/ jco.2005.02.8852

Bertelsen CA, Neuenschwander AU, Jansen JE, Wilhelmsen M, Kirkegaard-Klitbo A, Tenma JR, Bols B, Ingeholm P, Rasmussen LA, Jepsen LV, Iversen ER, Kristensen B, Gogenur I (2015) Disease-free survival after complete mesocolic excision compared with conventional colon cancer surgery: a retrospective, population-based study. Lancet Oncol 16(2):161-168. https://doi. org/10.1016/s1470-2045(14)71168-4

Bregni G, Akin Telli T, Camera S, Deleporte A, Moretti L, Bali AM, Liberale G, Holbrechts S, Hendlisz A, Sclafani F (2020) Adjuvant chemotherapy for rectal cancer: Current evidence and recommendations for clinical practice. Cancer Treat Rev 83:101948-101948. https://doi.org/10.1016/j.ctrv.2019.101948

Brierley JDGM, Wittekind Ch (eds) (2017) Union for International Cancer Control (UICC). TNM Classification of Malignant Tumors, 8th edn. Wiley, Hoboken
Charlson ME, Pompei P, Ales KL, MacKenzie CR (1987) A new method of classifying prognostic comorbidity in longitudinal studies: development and validation. J Chronic Dis 40(5):373-383

Chen SL, Bilchik AJ (2006) More extensive nodal dissection improves survival for stages I to III of colon cancer: a population-based study. Ann Surg 244(4):602-610. https://doi.org/10.1097/01. sla.0000237655.11717.50

de Weger VA, Turksma AW, Voorham QJ, Euler Z, Bril H, van den Eertwegh AJ, Bloemena E, Pinedo HM, Vermorken JB, van Tinteren H, Meijer GA, Hooijberg E (2012) Clinical effects of adjuvant active specific immunotherapy differ between patients with microsatellite-stable and microsatellite-instable colon cancer. Clin Cancer Res 18(3):882-889. https://doi.org/10.1158/1078-0432. Ccr-11-1716

Gaupset R, Nesgaard JM, Kazaryan AM, Stimec BV, Edwin B, Ignjatovic D (2018) Introducing anatomically correct CT-guided laparoscopic right colectomy with D3 anterior posterior extended mesenterectomy: initial experience and technical pitfalls. J Laparoendosc Adv Surg Tech A 28(10):1174-1182. https://doi. org/10.1089/lap.2018.0059

GBD 2017 Colorectal Cancer Collaborators (2019) The global, regional, and national burden of colorectal cancer and its attributable risk factors in 195 countries and territories, 1990-2017: a systematic analysis for the Global Burden of Disease Study 2017. Lancet Gastroenterol Hepatol 4(12):913-933. https://doi. org/10.1016/s2468-1253(19)30345-0

Gill S, Loprinzi CL, Sargent DJ, Thome SD, Alberts SR, Haller DG, Benedetti J, Francini G, Shepherd LE, Francois Seitz J, Labianca R, Chen W, Cha SS, Heldebrant MP, Goldberg RM (2004) Pooled analysis of fluorouracil-based adjuvant therapy for stage II and III colon cancer: who benefits and by how much? J Clin Oncol 22(10):1797-1806. https://doi.org/10.1200/jco.2004.09.059

Glimelius B, Dahl O, Cedermark B, Jakobsen A, Bentzen SM, Starkhammar H, Gronberg H, Hultborn R, Albertsson M, Pahlman L, Tveit KM (2005) Adjuvant chemotherapy in colorectal cancer: a joint analysis of randomised trials by the Nordic Gastrointestinal Tumour Adjuvant Therapy Group. Acta Oncol 44(8):904-912. https://doi.org/10.1080/02841860500355900

Glynne-Jones R, Wyrwicz L, Tiret E, Brown G, Rödel C, Cervantes A, Arnold D, Committee EG (2017) Rectal cancer: ESMO Clinical Practice Guidelines for diagnosis, treatment and follow-up. Ann Oncol 28(suppl_4):iv22-iv40. https://doi.org/10.1093/annonc/ $\operatorname{mdx} 224$

Goldstein NS (2002) Lymph node recoveries from 2427 pT3 colorectal resection specimens spanning 45 years: recommendations for a minimum number of recovered lymph nodes based on predictive probabilities. Am J Surg Pathol 26(2):179-189. https://doi. org/10.1097/00000478-200202000-00004

Heald RJ (1988) The 'Holy Plane' of rectal surgery. J R Soc Med 81(9):503-508

Helsedirektoratet (2019). 2020 (24.01): Norweigan guidelines for colorectal cancer. https://www.helsedirektoratet.no/retningsli njer/kreft-i-tykktarm-og-endetarm-handlingsprogram/IS\%25202 $849 \% 25202820$ Nasjonalt $\% 25202820$ handlingsprogram $\% 25202$ $820 \mathrm{kreft} \% 25202820 \mathrm{i} \% 25202820$ tykktarm\%25202820og\%25202 820endetarm.pdf/_/attachment/inline/202844a202845fa20284 8e-202848d202876-204618-202898b202843-202843af202845a 202885b202876e:202844c202844a202829f202871e202847a 202868ff202893a202819dd282848f202836a202849abff202 881/IS-202849\%25202820Nasjonalt\%25202820handlingspro gram\%25202820kreft\%25202820i\%25202820tykktarm\%25202 820og\%25202820endetarm.pdf (Cited Feb 202805 202020)

Hohenberger W, Weber K, Matzel K, Papadopoulos T, Merkel S (2009) Standardized surgery for colonic cancer: complete mesocolic excision and central ligation-technical notes and 
outcome. Colorectal Dis 11(4):354-364. https://doi.org/10.111 1/j.1463-1318.2008.01735.x (discussion 364-355)

Ishiyama Y, Maeda C, Shimada S, Kudo SE (2020) Propensity-scorematched analysis of short- and long-term outcomes in patients with an ileocolic artery crossing anterior vs posterior to the superior mesenteric vein during curative resection for right-sided colon cancer. Surg Endosc. https://doi.org/10.1007/s00464-019-07333-5

Iveson T, Boyd KA, Kerr RS, Robles-Zurita J, Saunders MP, Briggs AH, Cassidy J, Hollander NH, Tabernero J, Haydon A, Glimelius B, Harkin A, Allan K, McQueen J, Pearson S, Waterston A, Medley L, Wilson C, Ellis R, Essapen S, Dhadda AS, Harrison M, Falk S, Raouf S, Rees C, Olesen RK, Propper D, Bridgewater J, Azzabi A, Farrugia D, Webb A, Cunningham D, Hickish T, Weaver A, Gollins S, Wasan H, Paul J (2019) 3-month versus 6-month adjuvant chemotherapy for patients with high-risk stage II and III colorectal cancer: 3-year follow-up of the SCOT noninferiority RCT. Health Technol Assess 23(64):1-88. https://doi. org/10.3310/hta23640

Kelder W, Inberg B, Schaapveld M, Karrenbeld A, Grond J, Wiggers T, Plukker JT (2009) Impact of the number of histologically examined lymph nodes on prognosis in colon cancer: a populationbased study in the Netherlands. Dis Colon Rectum 52(2):260-267. https://doi.org/10.1007/DCR.0b013e3181979164

Kim JC, Lee KH, Yu CS, Kim HC, Kim JR, Chang HM, Kim JH, Kim JS, Kim TW (2004) The clinicopathological significance of inferior mesenteric lymph node metastasis in colorectal cancer. Eur J Surg Oncol 30(3):271-279. https://doi.org/10.1016/j. ejso.2003.12.002

Laurie JA, Moertel CG, Fleming TR, Wieand HS, Leigh JE, Rubin J, McCormack GW, Gerstner JB, Krook JE, Malliard J et al (1989) Surgical adjuvant therapy of large-bowel carcinoma: an evaluation of levamisole and the combination of levamisole and fluorouracil. The North Central Cancer Treatment Group and the Mayo Clinic. J Clin Oncol 7(10):1447-1456. https://doi.org/10.1200/ jco.1989.7.10.1447

Le Voyer TE, Sigurdson ER, Hanlon AL, Mayer RJ, Macdonald JS, Catalano PJ, Haller DG (2003) Colon cancer survival is associated with increasing number of lymph nodes analyzed: a secondary survey of intergroup trial INT-0089. J Clin Oncol 21(15):29122919. https://doi.org/10.1200/jco.2003.05.062

Leijssen LGJ, Dinaux AM, Amri R, Taylor MS, Deshpande V, Bordeianou LG, Kunitake H, Berger DL (2019) Impact of intramural and extramural vascular invasion on stage II-III colon cancer outcomes. J Surg Oncol 119(6):749-757. https://doi.org/10.1002/ jso. 25367

Li C, Pei Q, Zhu H, Tan F, Zhou Z, Zhou Y, Li Y, Pei H (2018) Survival nomograms for stage III colorectal cancer. Medicine (Baltimore) 97(49):e13239. https://doi.org/10.1097/md.0000000000013239

Moertel CG, Fleming TR, Macdonald JS, Haller DG, Laurie JA, Goodman PJ, Ungerleider JS, Emerson WA, Tormey DC, Glick JH et al (1990) Levamisole and fluorouracil for adjuvant therapy of resected colon carcinoma. N Engl J Med 322(6):352-358. https ://doi.org/10.1056/nejm199002083220602

Nesgaar JM, Stimec BV, Bakka AO, Edwin B, Bergamaschi R, Ignjatovic D (2019) Right colectomy with extended D3 mesenterectomy: anterior and posterior to the mesenteric vessels. Surg Technol Int 35:138-142
Nesgaard JM, Stimec BV, Soulie P, Edwin B, Bakka A, Ignjatovic D (2018) Defining minimal clearances for adequate lymphatic resection relevant to right colectomy for cancer: a post-mortem study. Surg Endosc 32(9):3806-3812. https://doi.org/10.1007/ s00464-018-6106-3

R core team (2013) R: A Language and Environment for Statistical Computing, R Foundation for Statistical Computing, Vienna, Austria. https://www.R-project.org/ (Cited Feb 06 2020)

RCPath (2020) The Royal college of Pathologists, Guidelines. https ://www.rcpath.org/uploads/assets/c8b61ba60-ae63f-43f61-85ffd 63ab69f17cfe66/G049-Dataset-for-histopathological-reportingof-colorectal-cancer.pdf (Cited Feb 006 2020)

Rosenberg R, Friederichs J, Schuster T, Gertler R, Maak M, Becker K, Grebner A, Ulm K, Hofler H, Nekarda H, Siewert JR (2008) Prognosis of patients with colorectal cancer is associated with lymph node ratio: a single-center analysis of 3,026 patients over a 25-year time period. Ann Surg 248(6):968-978. https://doi. org/10.1097/SLA.0b013e318190eddc

Spasojevic M, Stimec BV, Dyrbekk AP, Tepavcevic Z, Edwin B, Bakka A, Ignjatovic D (2013) Lymph node distribution in the $\mathrm{d} 3$ area of the right mesocolon: implications for an anatomically correct cancer resection. A postmortem study. Dis Colon Rectum 56(12):1381-1387. https://doi.org/10.1097/01.dcr.0000436279 $.18577 . \mathrm{d} 3$

Swanson RS, Compton CC, Stewart AK, Bland KI (2003) The prognosis of T3N0 colon cancer is dependent on the number of lymph nodes examined. Ann Surg Oncol 10(1):65-71. https://doi. org/10.1245/aso.2003.03.058

Tie J, Wang Y, Tomasetti C, Li L, Springer S, Kinde I, Silliman N, Tacey M, Wong HL, Christie M, Kosmider S, Skinner I, Wong R, Steel M, Tran B, Desai J, Jones I, Haydon A, Hayes T, Price TJ, Strausberg RL, Diaz LA Jr, Papadopoulos N, Kinzler KW, Vogelstein B, Gibbs P (2016) Circulating tumor DNA analysis detects minimal residual disease and predicts recurrence in patients with stage II colon cancer. Sci Transl Med 8(346):346ra392. https:// doi.org/10.1126/scitranslmed.aaf6219

Tie J, Cohen JD, Wang Y, Christie M, Simons K, Lee M, Wong R, Kosmider S, Ananda S, McKendrick J, Lee B, Cho JH, Faragher I, Jones IT, Ptak J, Schaeffer MJ, Silliman N, Dobbyn L, Li L, Tomasetti C, Papadopoulos N, Kinzler KW, Vogelstein B, Gibbs P (2019) Circulating tumor DNA analyses as markers of recurrence risk and benefit of adjuvant therapy for stage III colon cancer. JAMA Oncol 5(12):1710-1717. https://doi.org/10.1001/jamao ncol.2019.3616

Yang Y, Huang X, Sun J, Gao P, Song Y, Chen X, Zhao J, Wang Z (2015) Prognostic value of perineural invasion in colorectal cancer: a meta-analysis. J Gastrointest Surg 19(6):1113-1122. https ://doi.org/10.1007/s11605-015-2761-z

Publisher's Note Springer Nature remains neutral with regard to jurisdictional claims in published maps and institutional affiliations. 